\title{
Diabetes mellitus in pregnancy
}

\author{
Sunil Ambulkar, Parimal Tayde, Makarand Randive, Mukund Ganeriwal \\ Correspondence: Dr Parimal Tayde, Assistant Professor, Department of Endocrinology, \\ Superspeciality Hospital and Government Medical College, Nagpur, Maharashtra, India; \\ Email- Parimaltayde09@gmail.com
}

Distributed under Creative Commons Attribution-Share Alike 4.0 International.

\begin{abstract}
Pregnancy is a diabetogenic state due to rise of anti insulin hormones like human placental lactogen, steroids, progesterone and glucagon. In pregnancy normal values for fasting blood sugar level and post meal blood sugar level are less than normal population by approximately $10-20 \mathrm{mg} / \mathrm{dl}$. Universal screening is advocated for all women at 24/28 weeks. Those with high risks should be screened at initial visit and then at 24/28 weeks. Diagnostic values have changed over period of time. Pregestational diabetic patients should ideally be on insulin therapy before planning pregnancy. Long term follow up of gestational diabetes mellitus patients is must. This patient should undergo glucose tolerance test after 6 weeks of delivery and once in a year thereafter. Management of diabetes mellitus in pregnancy is a team approach.
\end{abstract}

Keywords: Pregnancy, diabetes, GTT.

In future there is going to be marked increase in the cases of diabetes in pregnancy. This is because of phenomenal increase in diabetic incidence and prevalence not only in middle age but also in the child bearing age group of 25 to 40 . At present $8-12 \%$ of urban and as well rural population of India is having diabetes ${ }^{1-5}$. With tendency towards late marriages and planning for a baby at later age, number of diabetic pregnancies will rise. With in vitro fertilization (IVF) facilities and use of progestational drugs this number will increase further ${ }^{6}$.

\section{Pathophysiology}

Pregnancy is a diabetogenic state. Those who are predisposed to develop diabetes mellitus (DM) in future for genetic reasons, family history of DM coupled with obesity will likely to have impaired glucoses intolerance or frank DM in pregnancy. This is because of rise of anti insulin hormones like human placental lactogen, steroids, progesterone and glucagon. Rise in free fatty acids and tumour necrosis factor alfa (TNF $\alpha$ ) also contribute to insulin resistance ${ }^{7}$. Those who cannot produce adequate insulin to counter these changes will develop DM.

\section{Types of DM in pregnancy}

DM can predate pregnancy. This is known as pregestational diabetes. Most cases belong to Type 2 D.M. But there is also a steady increase in Type $1 \mathrm{DM}$. When DM is detected or diagnosed for the first time in pregnancy (usually in predisposed individuals and at 24-28 weeks), it is termed as gestational diabetes mellitus (GDM) Usually it is type 2 or Non-Insulin Dependent DM. Rarely Type 1 DM can declare itself

Received: $15^{\text {th }}$ December 2016. Accepted: $25^{\text {th }}$ March 2017.

Ambulkar S, Tayde P, Randive M, Ganeriwal M. Diabetes mellitus in pregnancy. The New Indian Journal of OBGYN. 2017; 4(1): 4-9 
during pregnancy. The basic difference between pre gestational and gestational DM is for the neonatal outcome. If blood sugar level (BSL) are not well controlled in the first trimester, there are chances of congenital malformation (6-11\%) in pregestational DM and which are virtually non-existent in gestational diabetes ${ }^{8-10}$. This is because of teratogenic effects of high blood sugar on baby if BSL are not well controlled in first trimester. Other neonatal outcomes like macrosomia, other complications and as well maternal outcomes are same in both types if BSL not well controlled ${ }^{11}$. Normal pregnancy with normal BSL can have congenital malformation in $2 \%$ of pregnancies. ${ }^{12}$

\section{Gestational Diabetes Mellitus (GDM)}

GDM is a glucose intolerant state with onset or first recognition during pregnancy ${ }^{13}$. It includes clinically undetected Type 2 and rarely Type1 DM. Its incidence:

\section{Table 1: Normal and Abnormal BSL : Venous Plasma Glucose GOD/POD method}

\begin{tabular}{|c|c|c|}
\hline Categories & Fasting & Post Prandial \\
\hline Normal & $65-100 \mathrm{mg} / \mathrm{dl}$ & Upto $140 \mathrm{mg} / \mathrm{dl}$ \\
\hline \multicolumn{3}{|l|}{ Impaired Glucose } \\
\hline Tolerance & $65-100 \mathrm{mg} / \mathrm{dl}$ & $140-200 \mathrm{mg} / \mathrm{dl}$ \\
\hline \multicolumn{3}{|l|}{ Impaired Fasting } \\
\hline Blood Glucose & $100-125 \mathrm{mg} / \mathrm{dl}$ & Upto $140 \mathrm{mg} / \mathrm{dl}$ \\
\hline Diabetes Mellitus & $>/ 126 \mathrm{mg} / \mathrm{dl}$ & $>/ 200 \mathrm{mg} / \mathrm{dl}$ \\
\hline Pregnancy & $60-90 \mathrm{mg} / \mathrm{dl}$ & Upto $120 \mathrm{mg} / \mathrm{dl}$ \\
\hline
\end{tabular}

$3-14 \%$ and it is high in some ethnic groups ${ }^{14}$. There is increasing incidence in India, around $0.56 \%-6 \%$ according to study by Ramachandran A et al. ${ }^{5}$ In USA the incidence ranges from $6-7 \%$ and recently there has been a significant increase in all racial/ethnic groups. Native Americans, Asian Africans, Hispanics are at higher risk $\left(\right.$ Ferrara, 2007) ${ }^{15}$. It is associated with risk to the mother in short term and long term. Short term risk includes increased incidence of caesarian section up to $30 \%$, polyhydramnios in $20 \%$, preeclampsia in $20-30 \%$ and preterm labor. The gestational diabetes may recur in subsequent pregnancy and these patients are more prone for future development of diabetes mellitus. There is also risk to the baby. There are chances of unexplained still birth similar to Pre GDM. Other risks include fetal macrosomia (> $4 \mathrm{Kg}$ in weight), hypocalcaemia, hypoglycemia, jaundice, hyperviscosity, polycythemia, respiratory distress syndrome, cervical dystocia ${ }^{16}$. The patients may often need caesarian section for obstetric indication. If average BSL of mother during pregnancy is less than $100 \mathrm{mg} / \mathrm{dl}$, there is little risk.

Pregestational diabetes occurs in 0.4 to $2 \%$ of pregnancies. One needs to assess patient for DM control and screen for complications. The chances of congenital malformations are proportionate to rise in BSL and levels of Gly. HbA1c \% in uncontrolled DM. Although fetal screening is done with help of triple markers and 4 D USG, these methods are not 100\% sensitive or specific to rule out all congenital malformations. The investigations to screen for diabetic complications include ECG, fundus examination, lipids, e-GFR, microalbuminuria, Sr. creatinine, TSH.

The mainstay of management is conventional and usually multiple dose insulin therapy. Oral drugs like metformin and glibenclamide have been used with limited success ${ }^{17}$ but there is no universal acceptance for this. The screening for fetal abnormality includes double and triples markers and, 3 D or 4 D USG.

In pregnancy normal values for fasting blood sugar level (FBSL) and post meal blood sugar level (PMBSL) are less than normal population by approximately $10-20 \mathrm{mg} / \mathrm{dl}$. This is because of preferential transport of glucose across the placenta from maternal to fetal side. Normal values of blood sugar non pregnant and pregnant states and it's classification.is as given below in table 1 .

\section{Screening for DM}

Should we adopt a policy of universal screening? Indians are more predisposed to DM. Universal screening is advocated for all women at 24/28 weeks. Those with high risks should be screened at initial visit and then at $24 / 28$ weeks ${ }^{18}$. Screening test and diagnostic test values are shown in table 2 and 3 . Diagnostic test should follow if screening test is 
positive. Screening test with threshold of $130 \mathrm{mg} / \mathrm{dl}$ has nearly $100 \%$ sensitivity. National Diabetes Data Group (NDDG) and Carpenter \& Counstan were traditional criteria to diagnose GDM ${ }^{19}$. They were designed by using $100 \mathrm{gm}$ glucose and cumbersome three hour GTT. International association of Diabetes and Pregnancy Study Group (IADPSG) based on HAPO (Hyperglycaemias and Adverse Pregnancy Outcome Study) ${ }^{20}$ recommended newer stricter cut off for diagnosing DM. HAPO used 75 gm glucose \& 2 hour GTT which are given in table $4{ }^{21}$.

\section{Table 2: Screening for GDM}

$\circ$ Universal Screening at 24-28 Weeks to all Indian Women.

○ If at high risk: Screen at first prenatal visit and again

\begin{tabular}{|c|c|c|}
\hline \multicolumn{3}{|l|}{ Risk Factors } \\
\hline $\begin{array}{l}\text { Previous } \\
\text { GDM }\end{array}$ & Macrosomia & GHT \\
\hline Prediabetes & $\mathrm{BMI}>25$ & PCOS \\
\hline High Parity & Family history of DM & Age $>25$ \\
\hline $\begin{array}{l}\text { Prior } \\
\text { Stillbirth }\end{array}$ & Multiparity & Prior CS/ND \\
\hline
\end{tabular}

Diagnostic values have changed over period of time. These values only tell about the diagnostic criteria.

Table 3: Screening Test - Glucose Challenge Test (GCT)

\begin{tabular}{|c|c|c|}
\hline \multicolumn{3}{|c|}{ Screening Test : $50 \mathrm{gm} 1$ hour GCT (140 Vs 130) } \\
\hline Timing & Value & $\begin{array}{l}\text { Interpretation } \\
\text { Action }\end{array}$ \\
\hline 1 Hour & $<140 \mathrm{mg} / \mathrm{dl}$ & Normal(No GDM) \\
\hline 1 Hour & $140-200 \mathrm{mg} / \mathrm{dl}$ & Do 100 gm GTT \\
\hline 1 Hour & $>200 \mathrm{mg} / \mathrm{dl}$ & Diagnose as GDM \\
\hline \multicolumn{3}{|c|}{$\begin{array}{l}\text { Supplement with GlyHbA1C level. It indicates pre } \\
\text { existing hyperglycaemia of } 3 \text { months }\end{array}$} \\
\hline \multicolumn{3}{|c|}{ GlyHbA1C } \\
\hline Normal & Pre Diabetic & Diabetic \\
\hline$<5.6 \%$ & $5.7-6.4 \%$ & $6.5 \%$ or more \\
\hline
\end{tabular}

Patient should further be followed with FBS and PMBSL at least biweekly (at times daily). If FBS is more than $90 \mathrm{mg} / \mathrm{dl}$ and PMBSL is more than 120 $\mathrm{mg} / \mathrm{dl}$ then one needs start insulin therapy. This is

Table 4: Criteria for GDM

\begin{tabular}{llll}
\hline Timing & $\begin{array}{l}\text { Carpenter and } \\
\text { Counstan }\end{array}$ & NDDG & IADPSG \\
\hline & 100gm & 100 gm & 75 gm \\
& Glucose & Glucose & Glucose \\
\hline Fating & 95 & 105 & 95 \\
1 hour & 180 & 190 & 180 \\
2 hour & 155 & 165 & 155 \\
3 hour & 140 & 145 & - \\
All values in mg/dl. Plasma glucose values. Method: \\
GOD / POD
\end{tabular}

because BSL need to be maintained under strict control. This is because there is strong correlation

Table 5: Blood Glucose levels and incidence of macrosomia

Why these tight glycaemic targets?

Prospective study in Type 1 patients with pregnancy

\begin{tabular}{ll}
\hline Fasting Blood Sugar & Macrosomia \\
$>105 \mathrm{mg} / \mathrm{dl}$ & $28.6 \%$ \\
$95-105 \mathrm{mg} / \mathrm{dl}$ & $10 \%$ \\
$<95 \mathrm{mg} / \mathrm{dl}$ & $3 \%$ \\
\hline
\end{tabular}

between FBS and macrosomia. Table 5 shows the relationship between tight glycaemic control and the incidence of macrosomia.

\section{Management}

It includes medical nutritional therapy and insulin therapy. Calorie recommendation depends upon present weight and level of physical activity. Medical nutrition therapy is summarised in table 6. Sweeteners are not allowed during pregnancy. Although glibenclamide and metformin were used under trial conditions, they should be avoided. Initially diabetic diet trial for $3 / 7$ days in mild gestational DM patients is advocated. Insulin therapy should be started if BSL are not under control (If FBS > $90 \mathrm{mg} / \mathrm{dl}$ and PMBSL > $120 \mathrm{mg} / \mathrm{dl}$ ). 
Diabetic mothers should be asked to keep BSL diary. They should do at least FBS, PMBSL, before dinner BSL and RBS (whenever patients feel the BSL are low or may be high) at least alternate day or biweekly.

At times we require more frequent and daily monitoring especially in pregestational DM In certain uncontrolled GDM patients with high risk insulin

\section{Table 6: Medical Nutrition Therapy}

$>$ Ensure adequate calories for mother for adequate weight gain

$>$ Control glucose levels to near normal levels

$>$ Prevent starvation ketosis in early morning hours

$>$ Light aerobic exercise preferably walking.

$>$ Diabetic diet, divided over a period. Night Milk/Citrus Fruit

\begin{tabular}{lll}
\hline $\begin{array}{l}\text { Current Wt } \\
\text { in relation } \\
\text { to ideal } \\
\text { body weight }\end{array}$ & $\begin{array}{l}\text { Daily Caloric } \\
\text { Intake(Kcal/kg) }\end{array}$ & $\begin{array}{l}\text { Recommended } \\
\text { pregnancy weight } \\
\text { gain(Kg) }\end{array}$ \\
\hline$<80-90 \%$ & $36-40$ & $28-40$ \\
$80-120 \%$ & 30 & $25-35$ \\
(Ideal) & & \\
$120-150 \%$ & 24 & $15-25$ \\
$>150 \%$ & $12-18$ & $15-25$ \\
\hline
\end{tabular}

therapy can be started from day one. Pregestational DM patients should ideally be on insulin therapy before planning pregnancy. In fact pregnancy should be advised only if FBS < 90, PMBSL < 120 and Gly HbA $1 \mathrm{c}$ levels are less than $6.5 \%$. It has been general observation that pregnant diabetic mother whatever their level of education maintain BSL record diary well. Pregnant mothers should be asked to carry the diary to their physicians every time for adjustment of insulin dose. Table 7 shows the summary of target blood sugar levels and monitoring frequency. Frequent verbal or telephonic communication between patient and doctor is the key in management of DM in pregnancy. Patients should be made aware of hypoglycaemic symptoms and its immediate treatment. Conventional ( 1 or 2 doses of premixed preferably
50/50 insulin ) or Multiple Dose Insulin therapy ( three or more doses of Insulin, ( Mix insulin BBF \& BD \& Regular insulin before lunch or three doses of regular with long acting insulin at bedtime ) should be used.

Lispro, Aspart and Detemir are the safe and approved

Table 7: Target blood sugar levels and monitoring frequency

$>$ FBS $60-90 \mathrm{mg} / \mathrm{dl}$

$>$ PMBS : 2 Hours < $120 \mathrm{mg} / \mathrm{dl}$

$>8$ PM (Before Dinner) : $60-90 \mathrm{mg} / \mathrm{dl}$

$>$ SMBG at least 4 times a day/alternate day FBS,PMBSL, Before Dinner \& After Dinner, 3 am \&RBS

$>$ Watch for Hypoglycaemia: Reduce next dose by half.

$>$ Cost \&Compliance: Issues less formidable during pregnancy.

analogues which can be used in pregnancy ${ }^{22}$. Decision about timing of delivery should be best left with the obstetrician. DM is not an indication of caesarean section. It should be carried out for obstetric reasons. Glucose, potassium, insulin drip should be used during labour if labour is prolonged and RBS is more than 120 $\mathrm{mg} / \mathrm{dl}$. Some patients require betamethasone therapy for fetal lung maturation. This often leads to elevation in blood sugar levels. During this period, frequent monitoring of blood glucose levels and escalation of insulin dosages (double/triple) will be needed. Table 8 summarises the management at the time of delivery.

Long term follow up of GDM patients is must. This patient should undergo GTT after 6 weeks of delivery and once in a year thereafter ${ }^{7}$. Life style modifications should continue for life time as 30-50\% of GDM patients have chance of development of frank DM in next 10 years. Management of DM in pregnancy is a team approach. Close liaison between patient, obstetrician and physician is must for better outcome for the baby and as well as to the mother.

Conflict of interest: None. Disclaimer: Nil. 


\section{References}

1.Zargar AH, Sheikh MI, Bashir MI, Masoodi SR, Laway BA, Wani AI, et al. Prevalence of gestational diabetes mellitus in Kashmiri women from the Indian subcontinent. Diabetes Res Clin Pract. 2004; 66:139-45. [PubMed]

2.Seshiah V, Balaji V, Balaji MS, Paneerselvam A, Arthi $\mathrm{T}$, Thamizharasi M, et al. Prevalence of gestational diabetes mellitus in South India (Tamil Nadu) - A community based study. J Assoc Physicians India.2008; 56: 329-33. [PubMed]

3.Verma A, Singh B, Mengi V. Gestational diabetes in rural women of Jammu. Indian J Community Med. 2008; 33: 54-5. [PubMed]

4.Mohan V, Mahalakshmi MM, Bhavadharini B, Maheswari K, Kalaiyarasi G, Anjana RM, et al. Comparison of screening for gestational diabetes mellitus by oral glucose tolerance tests done in the non-fasting (random) and fasting states. Acta Diabetol. 2014; 51: 1007-13. [PubMed]

5.Ramachandran A, Snehalatha C. Current scenario of diabetes in India. J Diabetes. 2009; 1: 18-28. [PubMed]

6.Rebarber A, Istwan NB, Russo-Stieglitz K, ClearyGoldman J, Rhea DJ, Stanziano GJ, Saltzman DH. Increased incidence of gestational diabetes in women receiving prophylactic 17 alpha-hydroxyprogesterone caproate for prevention of recurrent preterm delivery. Diabetes Care. 2007; 30(9): 2277-80. Epub 2007 Jun 11.

7.Expert Committee on the Diagnosis and Classification of Diabetes Mellitus. Report of the Expert Committee on the Diagnosis and Classification of Diabetes Mellitus. Diabetes Care 26 (Suppl. 1): S5-S20. 2003

8.Galindo A, Burguillo AG, Azriel S, Fuente Pde L. Outcome of fetuses in women with pregestational diabetes mellitus. J Perinat Med. 2006; 34(4):323-31. [PubMed]

9.Aberg A, Westbom L, Källén B. Congenital malformations among infants whose mothers had gestational diabetes or preexisting diabetes. Early Hum Dev. 2001 Mar; 61(2):85-95. [PubMed]

10.Yang J, Cummings EA, O'connell C, Jangaard K. Fetal and neonatal outcomes of diabetic pregnancies. Obstet Gynecol. 2006 Sep; 108(3 Pt 1): 644-50.

11.Voldner N, Qvigstad E, Frøslie KF, Godang K, Henriksen T, Bollerslev J. Increased risk of macrosomia among overweight women with high gestational rise in fasting glucose. J Matern Fetal Neonatal Med. 2010 Jan; 23(1):74-81. [PubMed]

12.Centers for Disease Control and Prevention (CDC). Update on overall prevalence of major birth defects-Atlanta, Georgia, 1978-2005. MMWR Morb Mortal Wkly Rep. 2008; 57(1): 1-5. [PubMed]

13.Metzger BE, Coustan DR (Eds). Proceedings of the Fourth International Workshop-Conference on Gestational Diabetes Mellitus. Diabetes Care. 1998; 21 (Suppl 2): B1-B167.

14.Cunningham FG, Leveno KG, Bloom SL, Hauth JC, Gilsrab LC, Wenstrom KD. Williams Obstetrics. New York: McGraw Hill; 2005. pp. 1170-2.

15.Ferrara A. Increasing prevalence of gestational diabetes mellitus: a public health perspective. Diabetes Care. 2007; 30 (Suppl 2): S141-6.

16.Hale LA, Derya U, Betül Y, Mustafa A. Gestational diabetes mellitus screening and outcomes. J Turk Ger Gynecol Assoc. 2015; 16(1): 25-9.

17.Dhulkotia JS, Ola B, Fraser R, et al. Oral hypoglycemic agents vs insulin in management of gestational diabetes: a systematic review and meta analysis. Am J Obstet Gynecol. 2010; 203: 457.e1-9.

18.AACE Diabetes Mellitus Clinical Practice Guidelines Task Force. American Association of Clinical Endocrinologists medical guidelines for clinical practice for the management of diabetes mellitus: screening and diagnosis. Endocr Prac. 2007; 13 (Suppl 1): 10-12.

19.Carpenter MW, Coustan DR. Criteria for screening tests for gestational diabetes. Am J ObstetGynecol. 1982; 144: 768-73.

20.HAPO Study Cooperative Research Group. Hyperglycemia and adverse pregnancy outcomes. N Engl J Med 1991-2002; 2008: 358

21.International Association of Diabetes and Pregnancy Study Groups. International Association of Diabetes and Pregnancy Study Groups recommendations on the diagnosis and classification of hyperglycemia in pregnancy. Diabetes Care. 2010; 33(3): 676-82.

22.Hod M, Visser GHA, Damm P, Kaaja R, Dunne F, Hansen AP, Mersebach H. Safety and perinatal outcome in pregnancy: a randomized trial comparing insulin as part with human insulin in 322 subjects with type 1 diabetes. Diabetes. 2006; 53 (Suppl 1): A417. 
Professor, Department of Endocrinology,

Sunil Ambulkar ${ }^{1}$, Parimal Tayde ${ }^{2}$, Makarand Randive $^{3}$, Mukund Ganeriwal ${ }^{4}$

${ }^{1}$ Associate Professor, Department of Endocrinology, Superspeciality Hospital \& Government Medical College Nagpur; ${ }^{2}$ Assistant Superspeciality Hospital \& Government Medical College Nagpur; ${ }^{3}$ Senior Resident. Department of Endocrinology Superspeciality Hospital \& Government Medical College Nagpur; ${ }^{4} \mathrm{MD}$ (General Medicine) Consultant Physician, Nagpur. 